US shuttle

\section{NASA takes gloomy view of prospects}

\section{Washington}

COMPETITION between the United States and Europe to launch commercial payloads into Earth orbit is apparently bruising the National Aeronautics and Space Administration (NASA).

Administrator James Beggs of NASA told Congress last week that market prospects for the "Space Transportation System"' (NASAspeak for the shuttle) has been "very severely eroded" in the past year, so much so that NASA is having difficulty justifying a fifth orbiter in the foreseeable future.

Competition from Europe is not the only threat to the shuttle's commercial prospects but it is one of the most worrying to NASA. Beggs told the House of Representatives Science and Technology Committee that Europe was marketing the Ariane launch vehicle "very aggressively" and said he was "pessimistic about our ability to hold the lion's share of the market". In the past 14 months, Beggs said, "they've won five and we've won five and nobody else has won any"'. He also noted the recent decision of European science ministers to commit "around 1 billion" dollars to developing the Ariane 4 and Ariane 5 launchers.

But there are other problems for NASA's shuttle commercialization plans that stem from nearer home. Last year the Department of Defense decided to go ahead with its own expendable launch vehicle for military payloads, partly because it is disillusioned with the shuttle's reliability (numerous launches have had to be postponed) but also because of publicity surrounding shuttle launches. Press coverage of a military shuttle mission last month caused a political furore because Secretary of Defense Caspar Weinberger had said that news media must not so much as speculate about the objectives of the mission.

NASA had been expecting to launch at least two military payloads a year, roughly 10 per cent of planned missions for the next few years, and the loss of that source of income will hurt. Moreover, the National Oceanic and Atmospheric Administration (NOAA) has recently informed NASA that three meteorological satellites scheduled for launch in the shuttle will now be sent up on reconditioned Titan II rockets which have for years been sitting unused in silos as Minuteman missile launchers. Beggs noted dryly that the reconditioned rockets "are being offered around town" at cutprice rates but declined to comment on the financial wisdom of NOAA's decision to abandon the shuttle and to use its own launchers.
Beggs said that by the early 1990 s the country would probably be ready to start developing a second generation shuttle. Enough has already been learned for clear technological improvements to be incorporated, such as an improved thermal insulation system. Problems with the shuttle's heat-resistant tiles have caused extensive delays to launch schedules. A second generation shuttle might be ready for operation early in the next century, Beggs said. NASA's proposed budget for $1986(\$ 7,900$ million) will not mean the cancellation of any programmes, but development of the space station in 1986 will have to proceed at a "slightly slower pace" than had been anticipated, and no new projects will be started.

The Ariane 4 rocket now under development by the European Space Agency will be able to take a payload of around 4 metric tonnes into geosynchronous orbit; Ariane 5, which is still on the drawing board, would double that performance. In comparison, a shuttle payload can be up

\title{
Ariane up again
}

THE twelfth Ariane launch last Friday, using an Ariane-3 rocket, sucessfully placed two communications satellites into geostationary trasfer orbit: Arabsat F1 (1,195 $\mathrm{kg}$ launch mass) and Brasilsat $1(1,140 \mathrm{~kg})$. Arabsat will serve North Africa and the Middle East, using ground control stations at Dihrab (near Riyadh) and near Tunis. A second Arabsat is due to be launched later this year by the space shuttle. Brasilsat, naturally enough, will serve as a national Brazilian communications satellite, and will be controlled by the Tanguà ground station near Rio de Janeiro. The satellites are firsts both for the Arab states and for Brazil. Robert Walgate

to 30 tonnes, although extra motors are needed to boost a satellite from the shuttle's low orbit into geosynchronous orbit.

At present, NASA is flying experimental packages in the shuttle for potential commercial collaborators at bargain basement prices (some are free), but NASA has been directed to move towards a realistic pricing policy for commercial shuttle customers. As it does so, Ariane can be expected to enjoy an increasing cost advantage over the shuttle. At least, that is what NASA people fear and what Europeans hope.

Tim Beardsley

\section{Academics' doubts on research plan}

BrITISH academics familiar with the Natural Environment Research Council (NERC) say that the corporate plan contains good news (more emphasis on university support) and bad news (the continuing problem of declining funds). Two issues emerge as particularly contentious, the increased role of central administration and, among the Earth scientists, the apparent lack of commitment to the British Geological Survey.

Under the new plan, due to be published today (14 February) the role of central administrative staff would be enhanced in three ways. The number of such staff serving on the scientific committees would be increased, three scientific directors (possibly permanent) would be appointed to headquarters and the position of the NERC secretary as the conduit between the chairman of NERC and those below him would be confirmed. All three developments ring alarm bells. "I would be horrified to think that the scientific directors might be permanent members of staff I cannot think of anyone who could do the job", said one academic. Another feared that the chairman of the research council would be insulated from the directors of science. And there are complaints of "occasions when the lack of administrative staff on the scientific committees has produced problems of coordination, but to give them voting rights certainly enhances the degree to which control is centralized". One com- mon view is that the scientific directors could be an improvement, but that "anyone doing the job for more than four or five years could become a danger to the community".

The recent problems (see Nature 311, $499 ; 1984)$ of the systematic geological surveying by the British Geological Survey (BGS) have stimulated much public criticism of NERC by British academics. This concern is recognized but left virtually unanswered in the corporate plan. "Certainly the structure of BGS needs changing and contraction", said one senior geologist, "but what is desperately needed is some commitment to a systematic survey of the United Kingdom, both at the surface and at depth". The corporate plan promises "alternative approaches, with a concomitant loss of precision, if additional resources cannot be found". The document says elsewhere that "the council is reviewing its role of support of routine survey and data banking exercises: the latter will be pursued only on commission and/or where they underpin major programmes of research". That members of BGS are critical of their parent body, NERC, has become well known (see Nature 31 January, p.340). But there is now an influential body of academic opinion that believes that the strategic geological survey of the United Kingdom should be removed from NERC's control, perhaps to a government department.
Philip Campbell 